\title{
Mediatory effect of depression in the relations between cognitive reserve and cognitive abilities. Does a CR index matter?
}

\begin{abstract}
BACKGROUND
Cognitive reserve (CR) explains the level of cognitive functioning in healthy aging individuals or those with brain dysfunctions. Various CR indexes include objective (e.g. education level), subjective (e.g. self-report methods of life activity), and their combinations. Data showing the impact of $\mathrm{CR}$ on cognitive performance are unclear due to the relationship between CR and depressive mood as well as due to the impact of depressed mood on cognitive functions. The current study was designed to determine the link between three different $\mathrm{CR}$ indicators and cognitive abilities of adult Poles. The analyses took into account intensity of depression, as a mediator for these links. Additionally, the study was designed to assess whether or not the contents of the self-reported part of the $\mathrm{CR}$ index were of significance for the relations.
\end{abstract}

\section{PARTICIPANTS AND PROCEDURE}

The study was carried out in two unrelated groups of adult Poles (Group I, $n=130$; Group II, $n=90$ ). Assessment of CR took into account three indexes (CR based on self-reported activity in life, $\mathrm{CR}$ additionally containing information on formal education, and CR supplemented with information related to occupational activity). Cognitive capacity was assessed using the Montreal Cognitive Assessment Scale (MoCA), Vocabulary, as well as Digit Span Forward and Backwards. Intensity of depression was measured using Beck Depression Inventory (BDI) II. The self-report part of the questionnaire used to measure CR in Group I contained items mainly about past life and in Group II consisted of
more items about both past life and current activity.

\section{RESULTS}

The greater CR corresponds to higher scores in cognitive tasks and lower intensity of depressive mood. This is in line with previous research reporting that a higher level of the reserve may protect against mood disorders. Depression mediates the links between CR and the cognitive functions, reducing the positive impact of $\mathrm{CR}$. These relations were visible in Group I, where CR based on self-reported activity in life comprised items about (mainly) past life.

\section{CONCLUSIONS}

Self-report techniques used in CR assessment may be inadequate as a tool for describing the reserve, due to the link between self-report and emotional state. However, a more detailed self-report component of the $\mathrm{CR}$ indicator about both past and current life may correspond to a weaker or insignificant relation between $\mathrm{CR}$ and depressive mood as well as between depression and cognitive capacities. Varied approaches to operationalisation of CR result in discrepancies regarding the role of resources in the stabilisation and dynamics of cognitive status in ageing people and in clinical groups.

\section{KEY WORDS}

cognitive reserve; cognitive functioning; depression; adults

organization - Faculty of Pedagogy and Psychology, Institute of Psychology, Department of Clinical Psychology and Neuropsychology, Maria Curie-Skłodowska University, Lublin, Poland

AUthors' Contributions - A: Study design - B: Data collection - C: Statistical analysis · D: Data interpretation .

E: Manuscript preparation · F: Literature search · G: Funds collection

Corresponding AUthor - Prof. Ewa Małgorzata Szepietowska, Faculty of Pedagogy and Psychology, Institute of Psychology,

Department of Clinical Psychology and Neuropsychology, Maria Curie-Skłodowska University, 5 Litewski Square,

20-080 Lublin, Poland, e-mail: ewa.szepietowska@poczta.umcs.lublin.pl

TO CITE THIS ARTICLE - Szepietowska, E. M. (2019). Mediatory effect of depression in the relations between cognitive reserve and cognitive abilities. Does a CR index matter? Health Psychology Report, 7(3), 200-212. https://doi.org/

10.5114/hpr.2019.87865

RECEIVED 03.05.2019 · REVIEWED 17.08.2019 • ACCEPTED 17.08.2019 · PUBLISHED 12.09.2019 


\section{BACKGROUND}

The model of cognitive reserve (CR) and brain reserve (BR) proposed by Robert Katzman et al. (1988), Paul Satz (1993) and Yaakov Stern (2007) provides a starting point for explaining the effects of experience and knowledge gained over a lifetime, visible in cognitive functioning later in life or following brain damage. By assuming that greater CR enables optimisation of or compensation for cognitive deficits, the model can explain high cognitive capacities in healthy adults and in individuals from clinical groups. Findings of numerous studies link high CR to greater effectiveness of delayed verbal memory and executive functions in patients with Alzheimer disease and mild cognitive impairment (Darby, Brickhouse, Wolk, \& Dickerson, 2017), as well as better levels of attention and executive functions (Roldán-Tapia, García, Cánovas, \& León, 2012), delayed recall (Murphy \& O'Leary, 2010), working memory (Lojo-Seoane, Facal, Guàrdia-Olmos, Pereiro, \& Juncos-Rabadán, 2018), memory strategies (Frankenmolen, Fasotti, Kessels, \& Oosterman, 2018), and various cognitive domains (Opdebeeck, Martyr, \& Clare, 2016) in healthy adults. Different results were reported by Šneidere et al. (2018), who found CR to be unrelated to working and associative memory, attention, and psychomotor speed in Latvian seniors.

Studies take into account factors constituting CR indexes or isolated variables. These include: years of education, level of formal education (Farfel et al., 2013; Le Carret et al., 2003), occupation and its character (Adam, Bonsang, Grotz, \& Perelman, 2013; Chan et al., 2018), social, intellectual, physical and leisure activities (Mella, Grob, Döll, Ghisletta, \& de Ribaupierre, 2017), and socioeconomic status (Richards \& Sacker, 2003). Calculated indexes based on those factors are presented e.g. by the Cognitive Reserve Questionnaire (Rami et al., 2011), Cognitive Reserve Index Questionnaire (Nucci, Mapelli, \& Mondini, 2012), Cognitive Reserve Scale (Leon, García-García, \& Roldán-Tapia, 2014), and Index of Cognitive Reserve (Grotz, Seron, Wissen, \& Adam, 2017). In some cases the CR index takes into account cognitive competences acquired early in life, e.g. reading skills and language abilities (assessed using the National Adult Reading Test or subtest Vocabulary; Pettigrew et al., 2013), current activity in daily life (Activities of Daily Living - ADL), or activity in life and various experiences acquired (Lifetime of Experiences Questionnaire - LEQ; Valenzuela \& Sachdev, 2009). The above $\mathrm{CR}$ indexes are based on retrospective data, but in varied ways. The LEQ asks subjects to recall facts from three periods: 13-30, 30-65 and over 65 years of age (Valenzuela \& Sachdev, 2009). Other studies take into account activity and competences starting from 9 years of age (the prospective study focused on the subsequent 21 years) (Dekhtyar et al., 2015), from
18 years of age (Nucci et al., 2012) or "prior to the illness" in the case of subjects with dementia (Sobral, Pestana, \& Paúl, 2014). Varied approaches are used in describing isolated CR factors. For instance, Nucci et al. (2012) considered the level of responsibility at work; others specify the type of job (working with data, with people or with things) and the degree of intellectual involvement: from the lowest (collection) to the highest (synthesis) (Boots et al., 2015; Smart, Gow, \& Deary, 2014). Marengoni, Fratiglioni, Bandinelli, and Ferrucci (2011) define a CR index which reflects the socioeconomic status, understood as education level, type of occupation, financial status, and factors linked to work (e.g. stress). Multilingualism is thought to be an important component of CR (Bialystok, Craik, \& Freedman, 2007; Alladi et al., 2013; Guzmán-Vélez \& Tranel, 2015). Some findings did not confirm this effect (Calvo, García, Manoiloff, \& Ibáñez, 2016) and this is linked to the differences in the definition of multilingualism.

Reports on the effect of CR in cognitive functioning later in life are based on retrospective and prospective longitudinal studies involving two or more measurements over a period of three months (Valenzuela \& Sachdev, 2009), 18 months (Lojo-Seoane et al., 2018), two years (Evans et al., 2018), six years (Van Dijk, Van Gerven, Van Boxtel, Van der Elst, \& Jolles, 2008), seven years (Mazzeo et al., 2019), eight years (Zaninotto, Batty, Allerhand, \& Deary, 2018), 12 years (Soldan et al., 2017) or even 50 years (Plassman et al., 1995).

Despite the growing number of studies, research has produced ambiguous evidence as regards the role of $\mathrm{CR}$ in the current or future cognitive functioning. This is due to the aforementioned methodological differences (single measurement to identify effects of $\mathrm{CR}$ in the current cognitive capacities versus followup studies designed to identify the CR-related dynamics of cognitive abilities) (Chapko, McCormack, Black, Staff, \& Murray, 2018), as well as the varied CR indexes and their interactions. Meta-analyses (Meng \& D’Arcy, 2012; Prince et al., 2012) report no effects of education in subsequent cognitive abilities, or show that a lower level of education carries a risk of dementia while a higher level of education is linked with a better capacity for compensation of deficits, although the latter factor better explains cognitive abilities only in baseline measurements, and cannot be used to predict the dynamics of these capacities (Van Dijk et al., 2008; Zahodne et al., 2011). A positive effect of education as a CR indicator may be related to certain cognitive domains, e.g. psychomotor speed (Van Dijk et al., 2008). According to Marengoni et al. (2011), individuals with higher education yet performing physical jobs are more at risk of developing cognitive disorders, compared to individuals with a lower level of education. A low level of education combined with physical strain experienced at work is conducive to cognitive decline in the next three
Mediatory effect of depression in $C R$-cognitive ability relations 
Ewa Małgorzata Szepietowska years. The findings reported by Wilson et al. (2019) suggested that the level of education only to a limited degree can be treated as a factor predicting cognitive functioning at later stages of life. However, occupational activity, as compared to unemployment, promotes later cognitive status (Adam et al., 2013), but some studies report either an insignificant relationship (Prince et al., 2012) or protective effects produced only by work posing significant intellectual requirements (Boots et al., 2015; Correa Ribeiro, Lopes, \& Lourenço, 2013; Smart et al., 2014). Meanwhile, Singh-Manoux et al. (2011) observed greater cognitive deterioration in individuals holding higher professional positions. Boots et al. (2015) showed that individuals highly involved in their occupation, in particular those whose work required social activity, were characterised by greater brain and hippocampal atrophy, compared to individuals performing jobs with other requirements. The authors argue that work with people makes it possible to more effectively attenuate for the age-related brain pathologies. As regards the protective role of CR, Lavrencic, Churches, and Keage (2018a) and Lavrencic et al. (2018b) found that higher CR is associated with greater effectiveness of executive and attention processes only in baseline measurements.

The above data explain the need for a discussion related to the methodology of CR measurement. It has been pointed out that the factors contributing to $\mathrm{CR}$ are not of linear nature and are difficult to control (Malek-Ahmadi et al., 2017). Secondly, various CR indexes present different strength of relationships with cognitive functioning (Grotz et al., 2017). Thirdly, most information included in the questionnaires related to $\mathrm{CR}$ is assessed retrospectively and subjectively by study participants (Grotz et al., 2017). This results in a lack of accuracy in the process of accumulating the data despite the attempts to improve the objectivity of the measurement (e.g. by referring to an occupation classification system which should also reflect the socioeconomic status, cf. Marengoni et al., 2011). The subject describes their past activity, specifying its frequency, type of intellectual involvement and other CR related aspects. The description depends on the condition of the cognitive functions and on the emotional status; these variables tend to change with age. In the process of normal aging there is a visible decline in the episodic component of autobiographical memory, and an increasing tendency for semantic recall, i.e. generalisation of episodes (Piolino, Desgranges, Benali, \& Eustache, 2002). The cognitive deficits contribute to the tendency for generalisation and distortion of data related to one's life (Phillips \& Williams, 1997). Severe cognitive impairments (Mini-Mental State Examination [MMSE] $<10$ points) significantly reduce the ability to recall and evaluate life experiences (Logsdon, Gibbons, McCurry, \& Teri, 2002; Frank, Lenderking, Howard,
\& Cantillon, 2011). Properly designed questionnaires, taking into account the subjects' cognitive capacities, allow one to obtain reliable data about their lives (Trigg, Jones, \& Skevington, 2007). In addition to cognitive status, other factors, such as depression, may also adversely affect subjects' descriptions of their own lives (Lee, Park, \& Chey, 2018). These issues have not been investigated on a regular basis.

\section{RESEARCH OBJECTIVES AND QUESTIONS}

The level of CR is frequently based on self-report data. Knäuper et al. (2016) and Bravell, Zarit, and Johansson (2011) emphasised that responses provided or selected in self-report questionnaires depend on the subjects' cognitive and emotional status. Increased objectivity of CR factors is achieved by creating indexes which comprise data about the level of formal education and occupational activity (Knäuper et al., 2016; Jobe, 2009). The inclusion of objective data will help to control the impact of depression on the relation between $\mathrm{CR}$ and cognitive performance. Ambiguity of data reflecting the relation between $\mathrm{CR}$ and cognitive abilities may be explained by the diversity of CR factors. Therefore, the main purpose of the current study was to determine the links between three different $\mathrm{CR}$ indexes $\left(\mathrm{CR}_{\text {interview }}\right.$; $\left.\mathrm{CR}_{\text {interview_education }} ; \mathrm{CR}_{\text {interview_education_occupation }}\right)$ and cognitive abilities of adult Poles. The analyses took into account intensity of depression, as a mediator for these associations, given the fact that the relation of this condition to $\mathrm{CR}$ and cognitive abilities needs to be investigated in the context of the methods enabling measurement of resources. Additionally, the study was designed to assess whether or not the contents of the self-reported part of the CR index were of significance for the relations investigated. Despite the critical comments regarding self-report methods, these constitute an essential component of $\mathrm{CR}$ measures. With age it is increasingly difficult to fill in excessively long questionnaires related to one's life (Fox, Sidani, \& Streiner, 2007), and description of one's earlier experiences and activities is affected by one's mood and a tendency to apply one's semantic rather than episodic autobiographical knowledge. In view of the above, the study employed two versions of self-report techniques in assessment of $\mathrm{CR}$, i.e. the shorter version (in Group I) addressed seven domains of (mainly) past life, and the longer version (in Group II) included items related to living conditions during childhood and youth, current leisure time activities, and intellectual activity. Taking into account the above data, the assessment was performed for the two groups to investigate whether the relations described are affected by the type of the self-report component of the CR index. 


\section{OPERATIONALISATION OF VARIABLES}

The study took into account three groups of variables: a) independent variable: CR (three separate indicators: $\mathrm{CR}_{\text {interview }}$ - based on a subjective assessment of life activities; $\mathrm{CR}_{\text {interview education }}$ - taking into account data reported during an interview and formal education level; $\mathrm{CR}_{\text {interview education occupation }}$ - taking into account data reported during an interview, as well as formal education level and formal nature of occupational activity); b) mediator: intensity of depressive mood (BDI II); and c) dependent variables, in succession: overall level of cognitive abilities (total score in MoCA), efficiency of semantic memory and language functions (Vocabulary), immediate memory and attention (Digit Span Forward) and working memory (Digit Span Backwards). A survey questionnaire was also applied to acquire information about the subjects' demographics and health status (lack/presence as well as type of physical illnesses in the past and currently). To achieve the purpose of the study, the statistical analyses (SPSS Statistics version 24) included mediation analyses taking into account the scores of the two separate groups.

\section{PARTICIPANTS AND PROCEDURE}

\section{MATERIAL AND METHODS}

The study was carried out in two separate groups of adult Poles: Group I $(n=130)$ and Group II $(n=90)$. Three different CR indicators were used in the analyses: a) $\mathrm{CR}_{\text {interview }}$ was determined based, inter alia, on Cognitive Reserve Index questionnaire (CRIq; Nucci et al., 2012). In Group I it covered seven areas: current standard of living; physical activity during leisure time (past/present); social activity (past/present), sense of support currently received from others, sense of self-reliance in daily life. In Group II the questionnaire addressed 10 areas; it was supplemented with statements related to the standard of living during childhood and youth, as well as leisure activities and current intellectual activity. The responses were expressed on Likert scales, from 0 to 4 points, a higher score representing better evaluation of one's activity in a given area. The subjects selected one statement which, in their opinion, most successfully reflected their situation. The scores were in the range from 0 to 28 points in Group I and from 0 to 40 points in Group II; higher score reflected greater CR;

b) $\mathrm{CR}_{\text {interview education }}$ is the total of $\mathrm{CR}_{\text {interview }}$ and the level of formal education (i.e. primary education = 1 point; secondary $=2$ point; graduate and postgraduate $=3$ points). The scores were in the range of 1-31 points in Group I, and in the range of 1-43 points in Group II; higher score reflected greater $\mathrm{CR}$; c) $\mathrm{CR}$

comprised $\mathrm{CR}$ and the current occupational status (employed $=1$ point; unemployed $=0$ points $)$. The scores in Group I ranged from 1 to 32 points, and in Group II from 1 to 44 points; higher score reflected greater CR.

Cognitive functions were assessed using:

Montreal Cognitive Assessment Scale (MoCA), a test applied in screening assessment of cognitive functions (Nasreddine et al., 2005). It is considered to be more sensitive in identifying cognitive deficits than MMSE (Sokołowska et al., 2018). The maximum score (30 points) reflects a lack of cognitive dysfunctions, and a score of $25 / 26$ points is the recommended cut-off value differentiating individuals with and without cognitive deficits. Subtests of WAIS-R PL (Brzeziński et al., 2004), well-known tools applied in psychological assessments, are also recommended for neuropsychological examinations (Domańska, 2011). Assessment of mood was performed using Beck Depression Inventory II (Beck, Steer, \& Brown, 1996), its Polish version (2019), which allows one to examine the severity of depressive moods in the preceding two weeks. The self-report scale contains 21 items addressing emotional, cognitive, vegetative and somatic symptoms of depression. In the Polish version, raw scores above 25 points correspond to a mood disorder, and above 15 points reflect mood decline.

\section{CHARACTERISTICS OF THE STUDY GROUP}

Invitation to participate in the study was addressed to people 40 years of age or more. This age threshold was defined because a visible decrease in fluid abilities is observed between 40 and 50 years of age, and it correlates with changes in brain structures (Murman, 2015). After 40 years of age, it possible to observe effects of risk factors for brain pathology, and their expression depends on earlier experiences and lifestyles. Eligibility criteria defined for the study included: written consent to participate, health status and cognitive capacities allowing the subjects to participate and perform the tasks. Volunteers with existing chronic somatic disorders, dementia symptoms, and psychiatric problems were excluded from the study. The relevant data were obtained from a survey, from the participants and their relatives. Group I comprised adults $(n=130)$ ranging from 45 to 84 years of age $(M=59.60, S D=11.70, \min =45$, $\max =84)($ Table 1$)$. Over half of these were female subjects. More than half of the participants had completed secondary education, more than one in three subjects higher education and the others reported primary education. Years of education varied significantly within the group (ranging between 4 and 24 years; $M=12.80, S D=5.10$ ). The majority of the subjects were employed and married. Group II con-
Mediatory effect of depression in $C R$-cognitive ability relations 
Table 1

Participants' characteristics (Group I and Group II)

\begin{tabular}{|c|c|c|c|c|c|}
\hline \multirow[t]{2}{*}{ Factors } & \multicolumn{2}{|c|}{ Group I $(n=130)$} & \multicolumn{2}{|c|}{ Group II $(n=90)$} & \multirow{2}{*}{$\begin{array}{l}\chi^{2} \text { with Yates } \\
\text { correction }(p)\end{array}$} \\
\hline & $n$ & $\%$ & $n$ & $\%$ & \\
\hline \multicolumn{6}{|l|}{ Gender } \\
\hline male & 50 & 38.46 & 29 & 32.22 & $0.64(.42) n s$ \\
\hline female & 80 & 61.54 & 61 & 67.78 & \\
\hline \multicolumn{6}{|l|}{ Formal education } \\
\hline primary & 14 & 10.77 & 26 & 28.89 & $1.53(.27) n s$ \\
\hline secondary & 69 & 53.08 & 24 & 26.67 & \\
\hline higher & 47 & 36.15 & 40 & 44.44 & \\
\hline \multicolumn{6}{|l|}{ Occupational activity } \\
\hline unemployed & 47 & 36.15 & 31 & 34.44 & $0.01(.91) n s$ \\
\hline employed & 83 & 63.85 & 59 & 65.56 & \\
\hline \multicolumn{6}{|l|}{ Marital status } \\
\hline married & 111 & 85.38 & 73 & 81.11 & $0.53(.51) n s$ \\
\hline divorced/widowed & 19 & 14.62 & 17 & 18.89 & \\
\hline
\end{tabular}

Note. $n s$ - statistically insignificant relation

Table 2

Characteristics of results in CR, cognitive and emotional tests (Group $I-n=130$, Group $I I-n=90$ ): $M, S D$ and minimum-maximum

\begin{tabular}{|c|c|c|}
\hline Variables & $M(S D)$ & $\min -\max$ \\
\hline \multicolumn{3}{|c|}{ Group I $(n=130)$} \\
\hline $\mathrm{CR}_{\text {interview }}$ & $18.60(4.40)$ & $8-28$ \\
\hline $\mathrm{CR}_{\text {interview_education }}$ & $20.79(4.62)$ & $11-30$ \\
\hline $\mathrm{CR}_{\text {interview_education_occupation }}$ & $21.44(4.79)$ & $11-31$ \\
\hline Digits span forward & $6.10(1.90)$ & $1-10$ \\
\hline Digits span backwards & $5.40(2.00)$ & $2-12$ \\
\hline Vocabulary & $41.90(15.30)$ & $5-68$ \\
\hline $\mathrm{MoCA}$ & $26.10(3.60)$ & $11-30$ \\
\hline BDI II & 11.04 & $0-33$ \\
\hline \multicolumn{3}{|c|}{ Group II $(n=90)$} \\
\hline $\mathrm{CR}_{\text {interview }}$ & $24.20(5.97)$ & $11-38$ \\
\hline $\mathrm{CR}_{\text {interview_education }}$ & 27.37 & $13-41$ \\
\hline $\mathrm{CR}_{\text {interview_education_occupation }}$ & 28.02 & $14-42$ \\
\hline Digits span forward & $6.00(1.81)$ & $2-11$ \\
\hline Digits span backwards & $5.68(1.8)$ & $2-12$ \\
\hline Vocabulary & $46.21(14.09)$ & $42-68$ \\
\hline $\mathrm{MoCA}$ & $27.32(2.32)$ & $20-30$ \\
\hline BDI II & $10.53(7.40)$ & $0-35$ \\
\hline
\end{tabular}

sisted of 90 subjects, aged $40-81$ years $(M=53.04$, $S D=8.94)$; two in three subjects were female. The participants reported between 7 and 23 years of education, $M=14.47, S D=3.54)$. The groups did not differ in terms of the basic demographics and cognitive parameters, but there were differences related to age (Group I was older, $t=4.48, p=.001$ ) and years of education ( $t=2.68, p=.010$, i.e. Group II continued education for a longer period of time). Given the slightly different nature of the CR factors, intergroup comparisons were not performed.

\section{RESULTS}

The descriptive statistics (Table 2) show varied results in cognitive tests and in BDI II both in Group I and in Group II. Some participants assessed their resources as very high and some presented a low sense of $\mathrm{CR}$, regardless of the type of index $\left(\mathrm{CR}_{\text {interview, }}\right.$ $\left.\mathrm{CR}_{\text {interview_education, }} \mathrm{CR}_{\text {interview_education_occupation }}\right)$. In Group I $(n=130)$ there were no significant differences in the scores obtained by the females and the males in BDI II and in the cognitive tests. However, the women obtained poorer results in all the $\mathrm{CR}$ indicators: $\mathrm{CR}_{\text {interview }}$ $\left(M_{\text {females }}=17.70, S D=4.33 ; M_{\text {males }}=19.90, S D=4.20\right.$, $t=-2.73, p=.007) ; \mathrm{CR}_{\text {interview_education }}\left(M_{\text {females }}=19.90\right.$, $\left.S D=4.52, M_{\text {males }}=22.20, S D=4.50, t=-2.56, p=.020\right)$; $\mathrm{CR}_{\text {interview_education_occupation }}\left(M_{\text {females }}=2.60, S D=4.72\right.$, $\left.M_{\text {males }}=22.80, S D=4.60, t=-2.54, p=.020\right)$. The findings in Group II $(n=90)$ showed no sex-related differences in the three indexes, in BDI II or the cognitive tests. 


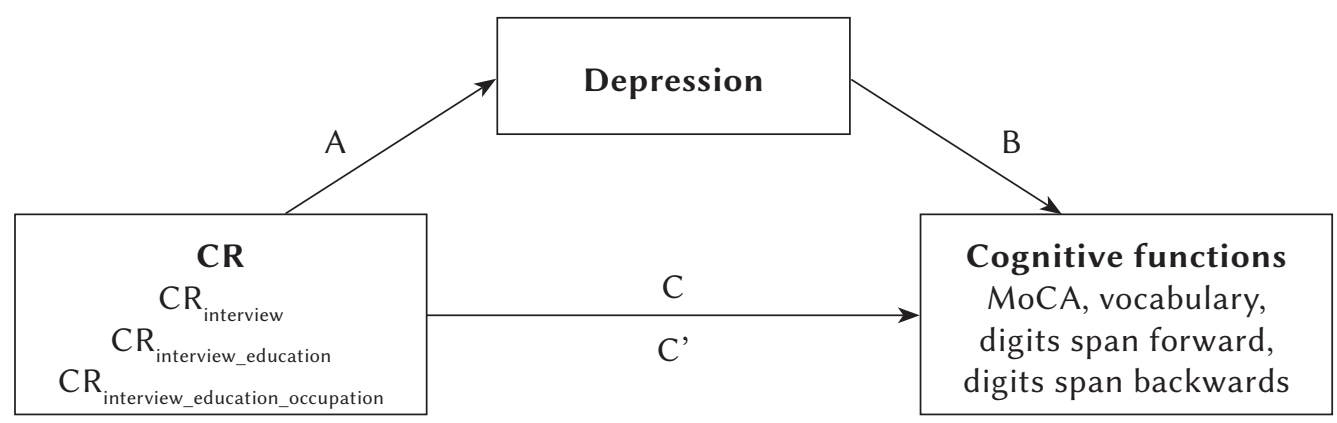

Figure 1. Overall mediation analysis scheme for Groups I and II.

Mediatory effect of depression in $C R$-cognitive ability relations
At a specified stage of the study a number of mediation analyses (Hayes, 2017) were performed, separately for Group I $(n=130)$ and Group II $(n=90)$. The level of CR (three consecutive indexes) was used as a predictor, the intensity of depression was the mediator and the scores in the cognitive tasks were applied as the dependent variable. The general model of the analyses is shown in Figure 1. Significance of the mediation was examined using the Aroian test, only in the cases where the mediation conditions were met, i.e. there were relationships between the predictor and the dependent variable (path C), between the mediator and the dependent variable (path B), and if by regressing the dependent variable on both the mediator and independent variable it was confirmed that the mediator is a significant predictor of the dependent variable, and the previously significant independent variable is now greatly reduced, if not non-significant (path $\mathrm{C}^{\prime}$ ). The data obtained through the analyses are shown in Table 3.

\section{DISCUSSION}

Generally, the findings show that, irrespective of the measurement method applied to determine $\mathrm{CR}$, greater reserve is consistently linked with higher scores in MoCA and Vocabulary (Group I and Group II), and in some cases with Digit Span Backwards and Forward (Group I). CR is negatively related to the intensity of depression, i.e. a higher level of $\mathrm{CR}$ corresponds to a lower level of depressive mood (in all the cases in Group I, and in some cases in Group II). Severity of depression mediates the relations between $\mathrm{CR}$ and task performance, reducing the positive effect of $\mathrm{CR}$ (only in Group I). These results are consistent with previous research reports (Opdebeeck et al., 2016; Szepietowska, 2019). Data from a few studies showed that a positive self-report is correlated with higher level of cognitive abilities (Amer, El Akkad, \& Hassan, 2014; Cruz et al., 2016) and negative self-report is associated with lower overall cognitive capacities
(MMSE) and verbal memory deficits (Wild, Mattek, Austin, \& Kaye, 2015).

Although they are in line with the discussion suggesting a positive relation of $\mathrm{CR}$ to cognitive performance, these data also suggest that self-assessment of various aspects of life activity is of limited value in the case of individuals with cognitive dysfunctions (Gerritesen, Steverink, Ooms, de Vet, \& Ribbe, 2007). In order to complete a self-report questionnaire one must be able to e.g. understand the items (Schwarz, 2006), recall the episodes, and effectively use one's working memory. With age people tend to generalise information based on the current situation (semantization) and the theory of the Self. This leads to errors in the reconstruction of past events, for example individuals who in their own opinion are socially active at present will assess their activity from the time of youth in the same way (Schwarz, 2006). Cognitive deficits, which may increase with age or due to clinical conditions, make it more difficult to address the contents of the items and to choose a response (Altschuler et al., 2009; Lukas, Niederecker, Günther, Mayer, \& Nikolaus, 2013). This effect was reflected in the current findings by the significant relationship between CR and semantic memory and linguistic functions. Hence, there may be a two-way link between cognitive abilities and CR, i.e. higher cognitive competences correspond to greater abilities in describing life experiences contributing to $\mathrm{CR}$, and vice versa - a greater CR corresponds to better cognitive capacities. There is a less clear relation between CR and immediate memory or working memory; it was observed only in Group I. This could be explained by the structure of the questionnaire, i.e. a small number of multiple-choice items of a rather general nature. Compared to more elaborate tasks, as well as those asking subjects to recall rather than recognise details, this type of task did not require significant involvement of working memory (Schwarz, 2006).

Furthermore, it was shown that depression is a mediator for the relation between $\mathrm{CR}$ and cognitive abilities, or that it is the only significant correlate for 
Table 3

Mediation analyses: results in Group I and Group II

\begin{tabular}{|c|c|}
\hline Group I $(n=130)$ & Group II $(n=90)$ \\
\hline \multicolumn{2}{|r|}{ MOCA } \\
\hline \multicolumn{2}{|r|}{$\mathrm{CR}_{\text {interview }}$} \\
\hline $\begin{array}{l}\text { A: } R^{2}{ }_{\text {adj }}=.11, F=15.87^{* * *}, \beta=-.34^{* * *} \\
\text { B: } \beta=-.47^{* *} \\
\text { C: } R^{2}{ }_{\text {adj }}=.12, F=16.7^{* * *}, \beta=.35^{* * *} \\
C^{\prime}: R^{2}{ }_{\text {adj }}=.31, F=27.9^{* * *}, \beta=.19^{*} \\
\text { Aroian test }=3.26, p=.001\end{array}$ & $\begin{array}{l}\mathrm{A}: R^{2}{ }_{\text {adj }}=.03, F=3.81^{*}, \beta=-.20^{*} \\
\mathrm{~B}: \beta=-.02 n s \\
\mathrm{C}: R^{2}{ }_{\text {adj }}=.16, F=16.9^{* * *}, \beta=.40^{* * *} \\
\mathrm{C}^{\prime}: R_{\text {adj }}^{2}=.14, F=8.39^{* * *}, \beta=.39^{* * *}\end{array}$ \\
\hline \multicolumn{2}{|r|}{$\mathrm{CR}_{\text {interview_education }}$} \\
\hline $\begin{array}{l}\mathrm{A}: R^{2}{ }_{\text {adj }}=.16, F=22.9^{* * *}, \beta=-.40^{* * *} \\
\mathrm{~B}: \beta=-.46^{* *} \\
\mathrm{C}: R^{2}{ }_{\text {adj }}=.13, F=19.45^{* * *}, \beta=.38^{* * *} \\
\mathrm{C}^{\prime}: R^{2}{ }_{\text {adj }}=.31, F=27.7^{* *}, \beta=.19^{*} \\
\text { Aroian test }=3.60, p<.001\end{array}$ & $\begin{array}{l}\mathrm{A}: R^{2}{ }_{\text {adj }}=.02, F=3.21 \mathrm{t}, \beta=-.19 \mathrm{t} \\
\mathrm{B}: \beta=-.18 \mathrm{~ns} \\
\mathrm{C}: R^{2}{ }_{\text {adj }}=.18, F=21.25^{* * *}, \beta=.44^{* * *} \\
\mathrm{C}^{\prime}: R^{2}{ }_{\text {adj }}=.17, F=10.52^{* * *}, \beta=.43^{* * *}\end{array}$ \\
\hline \multicolumn{2}{|r|}{$\mathrm{CR}_{\text {interview_education_occupation }}$} \\
\hline $\begin{array}{l}\text { A: } R^{2}{ }_{\text {adj }}=.19, F=29.22^{* * *}, \beta=-.46^{* * *} \\
\text { B: } \beta=-.44^{* *} \\
\text { C: } R^{2}{ }_{\text {adj }}=.16, F=24.53^{* * *}, \beta=.42^{* * *} \\
C^{\prime}: R^{2}{ }_{\text {adj }}=.32, F=28.7^{* * *}, \beta=.22^{* *} \\
\text { Aroian test }=3.73, p<.001\end{array}$ & $\begin{array}{l}\text { A: } R^{2}{ }_{\text {adj }}=.03, F=3.75^{*}, \beta=-.20^{*} \\
\text { B: } \beta=-.01 \mathrm{~ns} \\
\mathrm{C}: R^{2}{ }_{\text {adj }}=.19, F=21.63^{* * *}, \beta=.44^{* * *} \\
\mathrm{C}^{\prime}: R_{\text {adj }}^{2}=.18, F=10.7^{* *}, \beta=.42^{* *}\end{array}$ \\
\hline
\end{tabular}

Ewa Małgorzata Szepietowska

\section{VOCABULARY}

$\mathrm{CR}$
$\mathrm{A}: R^{2}{ }_{\text {adj }}=.12, F=15.87^{* * *}, \beta=-.34^{* * *}$
$\mathrm{B}: \beta=-.37^{* * *}$
$\mathrm{C}: R^{2}{ }_{\text {adj }}=.12, F=16.85^{* * *}, \beta=.35^{* * *}$
$C^{\prime}: R^{2}{ }_{\text {adj }}=.23, F=18.79^{* *}, \beta=.23^{* *}$
Aroian test $=2.87, p=.004$
$\mathrm{A}: R^{2}{ }_{\text {adj }}=.03, F=3.81^{*}, \beta=-.20^{*}$
$\mathrm{B}: \beta=-.11 \mathrm{~ns}$
$\mathrm{C}: R^{2}{ }_{\text {adj }}=.12, F=12.39^{* * *}, \beta=.35^{* * *}$
$C^{\prime}: R^{2}{ }_{\text {adj }}=.11, F=6.70^{* *}, \beta=.33^{* *}$

$\mathrm{CR}_{\text {interview_education }}$
$\mathrm{A}: R^{2}{ }_{\text {adj }}=.16, F=22.94^{* * *}, \beta=-.40^{* * *}$
B: $\beta=-.33^{* * *}$
A: $R^{2}$ adj $=.02, F=3.21 \mathrm{t}, \beta=-.19 \mathrm{t}$
$\mathrm{B}: \beta=-.09 \mathrm{~ns}$
$\mathrm{C}: R^{2}{ }_{\text {adj }}=.16, F=23.91^{* * *}, \beta=.41^{* * *}$
$C^{\prime}: R^{2}{ }_{\text {adj }}=.25, F=20.7^{* * *}, \beta=.27^{*}$
$\mathrm{C}: R^{2}{ }_{\text {adj }}=.15, F=16.7^{* * *}, \beta=.39^{* * *}$
$C^{\prime}: R^{2}{ }_{\text {adj }}=.15, F=8.83^{* * *}, \beta=.38^{* * *}$

Aroian test $=2.96, p=.003$

$\mathrm{CR}_{\text {interview_education_occupation }}$
$\mathrm{A}: R^{2}{ }_{\text {adj }}=.19, F=29.22^{* * *}, \beta=-.45^{* * *}$
B: $\beta=-.31^{* * *}$
$\mathrm{A}: R^{2}{ }_{\text {adj }}=.02, F=3.21 \mathrm{t}, \beta=-.19 \mathrm{t}$
$\mathrm{B}: \beta=-.09 \mathrm{~ns}$
$\mathrm{C}: R^{2}{ }_{\text {adj }}=.19, F=28.7^{* * *}, \beta=.44^{* * *}$
$C^{\prime}: R^{2}{ }_{\text {adj }}=.26, F=21.9^{* * *}, \beta=.31^{* * *}$
$\mathrm{C}: R^{2}{ }_{\mathrm{adj}}=.16, F=17.34^{* * *}, \beta=.41^{* * *}$
$C^{\prime}: R^{2}{ }_{\text {adj }}=.15, F=9.08^{* * *}, \beta=.39^{* * *}$

Aroian test $=2.90, p=.003$

\section{DIGITS SPAN FORWARD}
$\mathrm{A}: R_{\text {adj }}^{2}=.12, F=15.87^{* * *}, \beta=-.34^{* * *}$
$\mathrm{B}: \beta=-.23^{*}$
$\mathrm{C}: R^{2}{ }_{\text {adj }}=.09, F=13.53^{* * *}, \beta=.32^{* * *}$
$C^{\prime}: R^{2}{ }_{\text {adj }}=.13, F=10.24^{* * *}, \beta=.24^{* *}$
Aroian test $=2.08, p=.037$

$\mathrm{CR}_{\text {interview }}$
$\mathrm{A}: R^{2}{ }_{\text {adj }}=.03, F=3.81^{*}, \beta=-.20^{*}$
$\mathrm{B}: \beta=-.04 \mathrm{~ns}$
$\mathrm{C}: R^{2}{ }_{\text {adj }}=.02, F=2.24 \mathrm{~ns}, \beta$ ns
$\mathrm{C}^{\prime}: R^{2}{ }_{\text {adj }}=.00, F=1.17 \mathrm{~ns}, \beta \mathrm{ns}$

(Table 3 continues) 
Table 3

(Table 3 continued)
$\mathrm{A}: R^{2}{ }_{\text {adj }}=.16, F=22.9^{* * *}, \beta=-.40^{* * *}$
B: $\beta=-.20^{*}$
$\mathrm{C}: R^{2}{ }_{\text {adj }}=.11, F=16.4^{* * *}, \beta=.35^{* * *}$
$C^{\prime}: R^{2}{ }_{\text {adj }}=.14, F=10.88^{* * *}, \beta=.27^{*}$
$\mathrm{A}: R^{2}{ }_{\text {adj }}=.02, F=3.21 \mathrm{t}, \beta=-.19 \mathrm{t}$
$\mathrm{B}: \beta=-.04 \mathrm{~ns}$
$\mathrm{C}: R^{2}{ }_{\text {adj }}=.02, F=2.56 \mathrm{~ns}, \beta$ ns
Aroian test $=1.97, p=.048$
$\mathrm{C}^{\prime}: R^{2}{ }_{\text {adj }}=.01, F=1.33 n s, \beta n s$

$\mathrm{CR}_{\text {interview education }}$

CR

interview_education_occupation
$\mathrm{A}: R^{2}$ adj $=.19, F=29.22^{* * *}, \beta=-.45^{* * *}$
B: $\beta=-.19^{*}$
$\mathrm{A}: R^{2}{ }_{\text {adj }}=.02, F=3.21 \mathrm{t}, \beta=-.19 \mathrm{t}$
B: $\beta=-.04 n s$
$\mathrm{C}: R^{2}{ }_{\text {adj }}=.02, F=2.39 \mathrm{~ns}, \beta \mathrm{ns}$
$\mathrm{C}: R^{2}{ }_{\text {adj }}=.12, F=16.57^{* * *}, \beta=.35^{* * *}$
$C^{\prime}: R^{2}{ }_{\text {adj }}=.14, F=10.61^{* * *}, \beta=.26^{* *}$
$\mathrm{C}^{\prime}: R^{2}{ }_{\text {adj }}=.01, F=1.24 \mathrm{~ns}, \beta$ ns

Mediatory effect of depression in $C R$-cognitive ability relations
$\mathrm{A}: R^{2}{ }_{\text {adj }}=.12, F=15.87^{* * *}, \beta=-.34^{* * *}$
B: $\beta=-.36^{* * *}$
$\mathrm{C}: R^{2}{ }_{\text {adj }}=.01, F=1.49 \mathrm{~ns}, \beta$ ns
$C^{\prime}: R^{2}{ }_{\text {adj }}=.11, F=8.72^{* * *}, \beta=.01 \mathrm{~ns}$

DIGITS SPAN BACKWARDS

$\mathrm{CR}_{\text {in }}$
A: $R_{\text {adj }}^{2}=.03, F=3.81^{*}, \beta=-.20^{*}$
B: $\beta=-.03 \mathrm{~ns}$
$\mathrm{C}: R^{2}{ }_{\text {adj }}=-.01, F=.59 \mathrm{~ns}, \beta \mathrm{ns}$
$\mathrm{C}^{\prime}: R^{2}{ }_{\text {adj }}=-.02, F=.34 \mathrm{~ns}, \beta=.01 \mathrm{~ns}$

$\mathrm{CR}$
$\mathrm{A}: R^{2}{ }_{\text {adj }}=.16, F=22.94^{* * *}, \beta=-.40^{* * *}$
B: $\beta=-.35^{* * *}$
$\mathrm{C}: R^{2}{ }_{\text {adj }}=.02, F=3.10 \mathrm{~ns}, \beta$ ns
$C^{\prime}: R^{2}{ }_{\text {adj }}=.12, F=8.73^{* * *}, \beta n s$
$\mathrm{A}: R^{2}{ }_{\text {adj }}=.02, F=3.21 \mathrm{t}, \beta=-.19 \mathrm{t}$
$\mathrm{B}: \beta=-.01 \mathrm{~ns}$
$\mathrm{C}: R^{2}{ }_{\text {adj }}=.00, F=1.32 \mathrm{~ns}, \beta$ ns
$C^{\prime}: R^{2}{ }_{\text {adj }}=-.01, F=0.65 n s, \beta=.12 n s$

$\mathrm{CR}_{\text {interview_education_occupation }}$
$\mathrm{A}: R^{2}{ }_{\text {adj }}=.02, F=3.21 \mathrm{t}, \beta=-.19 \mathrm{t}$
$\mathrm{B}: \beta=.01 \mathrm{~ns}$
$\mathrm{C}: R^{2}{ }_{\text {adj }}=.00, F=1.27 n s, \beta$ ns
$C^{\prime}: R_{\text {adj }}^{2}=-.01, F=0.63 n s, \beta=.12 n s$

Aroian test $=2.96, p=.003$

Note. ${ }^{*} p<.05,{ }^{* *} p<.01,{ }^{* * *} p<.001, \mathrm{t}-$ statistical tendency, $n s-$ not significant

this ability. Severity of depressive mood plays a negative role in descriptions of life experiences (Beck, Steer, \& Brown, 2019). Negative mood promotes less favourable assessment of various aspects of functioning which are taken into account in CR indexes (Sivertsen, Bjørkløf, Engedal, Selbæk, \& Helvik, 2015). It also directly impairs cognitive functions: episodic and working memory, attention, and delayed recall (Vinkers, Gussekloo, Stek, Westendorp, \& van der Mast, 2004; Saenz, Garcia, \& Downer, 2018). Greater CR mitigates the impact of negative mood on cognitive abilities (Opdebeeck, Quinn, Nelis, \& Clare, 2015). The present findings suggest that current negative emotional state impairs the positive relation between $\mathrm{CR}$ and cognitive abilities and/or adversely affects some aspects of cognitive ability (Atkinson, Zibin, \& Chuang, 1997). Hence, negative mood is a mediator or moderator of relations between $\mathrm{CR}$ and some aspects of cognitive performance.

Is the $\mathrm{CR}$ index important from the viewpoint of the identified effects? As a reminder, the study applied three $\mathrm{CR}$ indexes, the first one $\left(\mathrm{CR}_{\text {interview }}\right)$ based only on a subjective assessment of life activities, and the other two supplemented with objective information about the level of education $\left(\mathrm{CR}_{\text {interview education }}\right)$ and current occupational activity $\left(\mathrm{CR}_{\text {interview_education_occupation }}\right)$. Additionally, the questionnaires used in Group I and Group II were slightly different; the former was expanded to include current life activity data. Examination of the relations between $\mathrm{CR}$ and depression in the two groups (paths A) clearly shows that they are weaker or insignificant in Group II, where the questionnaire contained more items related to the past and present activity in life. It can be speculated 
Ewa Małgorzata Szepietowska that a more detailed self-report component of the CR indicator about both past and current life may correspond to a weaker or insignificant relation between CR and depressive mood as well as between depression and cognitive capacities.

This result may be linked to the problem of selfreport techniques applied in the diagnostic process, in particular with reference to the elderly (Knäuper et al., 2016). Wheeler and Reis (1991) pointed out that it is extremely difficult to summarise one's life experiences in a brief questionnaire and that recalling facts from various stages of life involves their emotional assessment or reflection rather than reminiscences. Cognitive control of current data (covered by the questionnaire used in Group II) is easier; additionally, they are less emotionally engaging. There is also a different relationship between BDI II and cognitive functions (path B), rather strong in Group I and insignificant in Group II. These findings suggest that the relations of the factors of $\mathrm{CR}$, cognitive functions and depression, slightly different in the two groups, reflect the contents of the questionnaires: $\mathrm{CR}$ indexes, depending on the structure of the self-report part, shape the relations with cognitive efficiency in a different way. Furthermore, the groups' results may have been affected by specific variables, such as sex and medical history, which were not controlled for in the analyses.

In summary, the current findings are related to the problem of the inconsistent evidence regarding the role of $\mathrm{CR}$ in explaining the current cognitive status and its stabilisation in subsequent years, which is linked to the various CR indexes applied (data based on a self-description of past life activities, data related to education, combinations of these two factors, etc.) (Grotz et al., 2017; Jones et al., 2011). To determine the role of CR in shaping cognitive capacities of people at later stages of life it is necessary to develop more objective CR indicators that minimise the effects of mood. Comprehensive questionnaires, matching the specific nature of the subjects' cultural environment (Darwish, Farran, Assaad, \& Chaaya, 2018), will facilitate acquisition of such evidence.

\section{CONCLUSIONS}

1. A higher level of $C R$, irrespective of the related index, is conducive to efficiency of semantic memory, language abilities, immediate memory and overall level of cognitive functioning.

2. Depressive mood incidentally is negatively associated with cognitive performance.

3. Higher level of $\mathrm{CR}$ is linked to lower intensity of depressive mood.

4. Depressive mood decreases the positive impact of $\mathrm{CR}$ on cognitive functions. Self-report techniques used as the only indicator in CR assessment may be inadequate as a tool for describing the reserve, due to the association between self-report and the emotional state. A more extensive self-report questionnaire used in CR assessment regarding both past and current life may correspond to weaker relationships between CR and depression as well as between depression and cognitive capacities.

5. Varied approaches to operationalisation of $\mathrm{CR}$ result in discrepant data regarding the role of reserve in the stabilisation and dynamics of cognitive status in ageing people and in those representing clinical groups. It would be worthwhile to continue the research taking into account other, more objective, CR indexes.

\section{References}

Adam, S., Bonsang, E., Grotz, C., \& Perelman, S. (2013). Occupational activity and cognitive reserve: implications in terms of prevention of cognitive aging and Alzheimer's disease. Clinical Interventions in Aging, 8, 377-390. https://doi.org/10.2147/CIA. S39921

Alladi, S., Bak, T., Duggirala, V., Surampudi, B., Shailaja, M., Shukla, A., \& Kaul, S. (2013). Bilingualism delays age at onset of dementia, independent of education and immigration status. Neurology, 81, 1938-1944. https://doi.org/10.1212/01. wnl.0000436620.33155.a4

Altschuler, A., Picchi, T., Nelson, M., Rogers, J., Hart, J., \& Sternfeld, B. (2009). Physical activity questionnaire comprehension: lessons from cognitive interviews. Medicine and science in sports and exercise, 41, 336-343. https://doi.org/

Amer, M., El Akkad, R., \& Hassan, H. (2014). Is cognition a determinant of health related quality of life in community dwelling non demented elderly? Advances in Aging Research, 3, 339-348. https:// doi.org/10.4236/aar.2014.35044

Atkinson, M., Zibin, S., \& Chuang, H. (1997). Characterizing quality of life among patients with chronic mental illness: a critical examination of the self-report methodology. American Journal of Psychiatry, 154, 99-105. https://doi.org/10.1176/ajp.154.1.99

Beck, A. T., Steer, R., \& Brown, G. (1996). Manual for the Beck Depression Inventory II. San Antonio, TX: Psychological Corporation.

Beck, A. T., Steer, R., \& Brown, G. (2019). BDI-II. Podręcznik [BDI-II. Manual]. Warszawa: Pracownia Testów Psychologicznych Polskiego Towarzystwa Psychologicznego.

Bialystok, E., Craik, F., \& Freedman, M. (2007). Bilingualism as a protection against the onset of symptoms of dementia. Neuropsychologia, 45, 459-464. https://doi.org/10.1016/j.neuropsychologia.2006. 10.009

Bravell, M., Zarit, S., \& Johansson, B. (2011). Self-reported activities of daily living and performance- 
based functional ability: a study of congruence among the oldest old. European Journal of Ageing, 8, 199-209. https://doi.org/10.1007/s10433-011-0192-6

Brzeziński, J., Gaul, M., Hornowska, E., Jaworowska, A., Machowski, A., \& Zakrzewska, M. (2004). Skala Inteligencji D. Wechslera dla Dorostych. Wersja zrewidowana - renormalizacja WAIS-R (PL) [D. Wechsler Intelligence Scale for Adults. Revised version - renormalization WAIS-R (PL)]. Warszawa: Pracownia Testów Psychologicznych Polskiego Towarzystwa Psychologicznego.

Boots, E., Schultz, S., Almeida, R., Oh, J., Koscik, R., Dowling, M., Gallagher, C., Carlsson, C., Rowley, H., Bendlin, B., Asthana, S., Sager, M., Hermann, B., Johnson, S., \& Okonkwo, O. (2015). Occupational complexity and cognitive reserve in a middle-aged cohort at risk for Alzheimer's disease. Archives of Clinical Neuropsychology, 30, 634-642. https://doi. org/10.1093/arclin/acv041

Calvo, N., García, A., Manoiloff, L., \& Ibáñez, A. (2016). Bilingualism and cognitive reserve: a critical overview and a plea for methodological innovations. Frontiers in Aging Neuroscience, 7, 249. https://doi. org/10.3389/fnagi.2015.00249.

Chan, D., Shafto, M., Kievit, R., Matthews, F., Spink, M., Valenzuela, M., Cam-CAN, \& Henson, R. N. (2018). Lifestyle activities in mid-life contribute to cognitive reserve in late-life, independent of education, occupation, and late-life activities. Neurobiology of Aging, 70, 180-183. https://doi.org/ 10.1016/j.neurobiolaging.2018.06.012

Chapko, D., McCormack, R., Black, C., Staff, R., \& Murray, A. (2018). Life-course determinants of cognitive reserve (CR) in cognitive aging and dementia - a systematic literature review. Aging \& Mental Health, 22, 915-926. https://doi.org/10.10 80/13607863.2017.1348471

Correa Ribeiro, P., Lopes, C., \& Lourenço, R. (2013). Complexity of lifetime occupation and cognitive performance in old age. Occupational Medicine, 63, 556-562. https://doi.org/10.1093/occmed/kqt115

Cruz, B., de Resende, C., Carvalhaes, C., Cardoso, C., Teixeira, A., Rocha, F., \& Salgado, J. (2016). Interview-based assessment of cognition is a strong predictor of quality of life in patients with schizophrenia and severe negative symptoms. Brazilian Journal of Psychiatry, 38, 216-221. https://doi. org/10.1590/1516-4446-2015-1776

Darby, R., Brickhouse, M., Wolk, D., Dickerson, B., \& Alzheimer's Disease Neuroimaging Initiative (2017). Effects of cognitive reserve depend on executive and semantic demands of the task. Journal of Neurology, Neurosurgery and Psychiatry, 88, 794-802. https://doi.org/10.1136/jnnp-2017-315719

Darwish, H., Farran, N., Assaad, S., \& Chaaya, M. (2018). Cognitive reserve factors in a developing country: education and occupational attainment lower the risk of dementia in a sample of Leba- nese older adults. Frontiers in Aging Neuroscience, 10, 277. https://doi.org/10.3389/fnagi.2018.00277

Dekhtyar, S., Wang, H. X., Scott, K., Goodman, A., Koupil, I., \& Herlitz, A. (2015). A life-course study of cognitive reserve in dementia-from childhood to old age. The American Journal of Geriatric Psychiatry, 23, 885-896. https://doi.org/10.1016/j.jagp.2015. 02.002

Domańska, Ł. (2011). Kliniczne zastosowanie Skali Inteligencji dla Dorostych D. Wechslera w diagnozie neuropsychologicznej [Clinical application of D. Wechsler Adult Intelligence Scale in neuropsychological diagnosis]. In K. Wiejak \& G. Krasowicz-Kupis (Eds.), Kliniczne zastosowania skal inteligencji D. Wechslera [Clinical applications of D. Wechsler's intelligence scales] (pp. 126-136). Warszawa: Pracownia Testów Psychologicznych Polskiego Towarzystwa Psychologicznego.

Evans, I., Llewellyn, D., Matthews, F., Woods, R., Brayne, C., Clare, L., \& CFAS-Wales Research Team (2018). Social isolation, cognitive reserve, and cognition in healthy older people. PLoS One, 13, e0201008. https://doi.org/10.1371/journal.pone.0201008

Farfel, J., Nitrini, R., Suemoto, C., Grinberg, L., Ferretti, R., Leite, R., Tampellini, E., Lima, L., Farias, D., Neves, R., Rodriguez, R., Menezes, P., Fregni, F., Bennett, D., Pasqualucci, C., Jacob-Filho, W., \& Brazilian Aging Brain Study Group (2013). Very low levels of education and cognitive reserve: a clinicopathologic study. Neurology, 81, 650-657. https:// doi.org/10.1212/WNL.0b013e3182a08f1b

Fox, M. T., Sidani, S., \& Streiner, D. (2007). Using standardized survey items with older adults hospitalized for chronic illness. Research in Nursing \& Health, 30, 468-481. https://doi.org/10.1002/nur.20201

Frank, L., Lenderking, W., Howard, K., \& Cantillon, M. (2011). Patient self-report for evaluating mild cognitive impairment and prodromal Alzheimer's disease. Alzheimer's Research and Therapy, 3, 35. https://doi.org/10.1186/alzrt97

Frankenmolen, N., Fasotti, L., Kessels, R., \& Oosterman, J. (2018). The influence of cognitive reserve and age on the use of memory strategies. Experimental Aging Research, 44, 117-134. https://doi.org /10.1080/0361073X.2017.1422472

Gerritsen, D., Steverink, N., Ooms, M., de Vet, H., \& Ribbe, M. (2007). Measurement of overall quality of life in nursing homes through self-report: the role of cognitive impairment. Quality Life Research, 16, 1029-1037. https://doi.org/10.1007/s11136-0079203-7

Grotz, C., Seron, X., Wissen, M., \& Adam, S. (2017). How should proxies of cognitive reserve be evaluated in a population of healthy older adults? International Psychogeriatrics, 29, 123-136. https:// doi.org/10.1017/S1041610216001745

Guzmán-Vélezm, E., \& Tranel, D. (2015). Does bilingualism contribute to cognitive reserve? Cogni-
Mediatory effect of depression in $C R$-cognitive ability relations 
tive and neural perspectives. Neuropsychology, 29, 139-150. https://doi.org/10.1037/neu0000105

Hayes, A. (2017). Introduction to mediation, moderation, and conditional process analysis. Second edition: A regression-based approach. New York, NY: Guilford Press.

Jobe, J. (2009). Cognitive processes in self-report. In A. Stone, J. Turkkan, C. Bachrach, J. Jobe, H. Kurtzman, \& V. Cain (Eds.), The science of self-report (pp. 25-29). Abingdon: Taylor \& Francis.

Ewa Małgorzata Szepietowska son, A, \& Stern, $Y$. son, A., \& Stern, Y. (2011). Conceptual and measurement challenges in research on cognitive reserve. Journal of the International Neuropsychological Society, 17, 593-601. https://doi.org/10.1017/ S1355617710001748

Katzman, R., Terry, R., DeTeresa, R., Brown, T., Davies, P., Fuld, P., Renbing, X., \& Peck, A. (1988). Clinical, pathological, and neurochemical changes in dementia: a subgroup with preserved mental status and numerous neocortical plaques. Annals of Neurology, 23, 138-144. https://doi.org/10.1002/ ana.410230206

Knäuper, B., Carriere, K., Chamandy, M., Xu, Z., Schwarz, N., \& Rosen, N. (2016). How aging affects self-reports. European Journal of Ageing, 13, 185193. https://doi.org/10.1007/s10433-016-0369-0

Lavrencic, L., Churches, O., \& Keage, H. (2018a). Cognitive reserve is not associated with improved performance in all cognitive domains. Applied Neuropsychology: Adult, 25, 473-485. https://doi.org/ 10.1080/23279095.2017.1329146

Lavrencic, L., Richardson, C., Harrison, S., Muniz-Terrera, G., Keage, H., Brittain, K., Kirkwood, T., Jagger, C., Robinson, L., \& Stephan, B. (2018b). Is there a link between cognitive reserve and cognitive function in the oldest-old? The Journals of Gerontology: Series A, 73, 499-505. https://doi.org/10.1093/gerona/glx140

Le Carret, N., Lafont, S., Letenneur, L., Dartigues, J. F., Mayo, W., \& Fabrigoule, C. (2003). The effect of education on cognitive performances and its implication for the constitution of the cognitive reserve. Developmental Neuropsychology, 23, 317337. https://doi.org/10.1207/S15326942DN2303_1

Lee, J., Park, H., \& Chey, J. (2018). Education as a protective factor moderating the effect of depression on memory impairment in elderly women. Psychiatry Investigation, 15, 70-77. https://doi.org/10.4306/ pi.2018.15.1.70

León, I., García-García, J., \& Roldán-Tapia, L. (2014). Estimating cognitive reserve in healthy adults using the Cognitive Reserve Scale. PLoS One, 9, e102632. https://doi.org/10.1371/journal.pone.0102632

Logsdon, R., Gibbons, L., McCurry, S., \& Teri, L. (2002). Assessing quality of life in older adults with cognitive impairment. Psychosomatic Medicine, 64, 510-519. https://doi.org/10.1097/00006842-200205 000-00016

Lojo-Seoane, C., Facal, D., Guàrdia-Olmos, J., Pereiro, A., \& Juncos-Rabadán, O. (2018). Effects of cognitive reserve on cognitive performance in a followup study in older adults with subjective cognitive complaints. the role of working memory. Frontiers in Aging Neuroscience, 10, 189. https://doi.org/10.3389/ fnagi.2018.00189

Lukas, A., Niederecker, T., Günther, I., Mayer, B., \& Nikolaus, T. (2013). Self- and proxy report for the assessment of pain in patients with and without cognitive impairment: experiences gained in a geriatric hospital. Zeitschrift für Gerontologie \& Geriatrie, 46, 214-221. https://doi.org/10.1007/s00391013-0475-y

Malek-Ahmadi, M., Lu, S., Chan, Y., Perez, S., Chen, K., \& Mufson, E. (2017). Static and dynamic cognitive reserve proxy measures: interactions with Alzheimer's disease neuropathology and cognition. Journal of Alzheimer's Disease and Parkinsonism, 7, 390. https://doi.org/10.4172/2161-0460.1000390

Marengoni, A., Fratiglioni, L., Bandinelli, S., \& Ferrucci, L. (2011). Socioeconomic status during lifetime and cognitive impairment no-dementia in late life: the population-based aging in the Chianti Area (InCHIANTI) Study. Journal of Alzheimer's Disease, 24, 559-568. https://doi.org/10.3233/JAD-2011-101863

Mazzeo, S., Padiglioni, S., Bagnoli, S., Bracco, L., Nacmias, B., Sorbi, S., \& Bessi, V. (2019). The dual role of cognitive reserve in subjective cognitive decline and mild cognitive impairment: a 7-year follow-up study. Journal of Neurology, 266, 487497. https://doi.org/10.1007/s00415-018-9164-5

Mella, N., Grob, E., Döll, S., Ghisletta, P., \& de Ribaupierre, A. (2017). Leisure activities and change in cognitive stability: a multivariate approach. Brain Sciences, 7, 27. https://doi.org/10.3390/brainsci7030027

Meng, X., \& D’Arcy, C. (2012). Education and dementia in the context of the cognitive reserve hypothesis: a systematic review with meta-analyses and qualitative analyses. PLoS One, 7, e38268. https:// doi.org/10.1371/journal.pone.0038268

Murman, D. (2015). The impact of age on cognition. Seminars in Hearing, 36, 111-121. https://doi. org/10.1055/s-0035-1555115

Murphy, M., \& O'Leary, E. (2010). Depression, cognitive reserve and memory performance in older adults. International Journal of Geriatric Psychiatry, 25, 665-671. https://doi.org/10.1002/gps.2404

Nasreddine, Z., Phillips, N., Bédirian, V., Charbonneau, S., Whitehead, V., Collin, I., Cummings, J., \& Chertkow, H. (2005). The Montreal Cognitive Assessment, MoCA: a brief screening tool for mild cognitive impairment. Journal of American Geriatric Society, 53, 695-699. https://doi.org/10.1111/j. 1532-5415.2005.53221.x

Nucci, M., Mapelli, D., \& Mondini, S. (2012). The Cognitive Reserve Index questionnaire (CRIq): A new 
instrument for measuring the cognitive reserve. Aging Clinical and Experimental Research, 24, 218226. https://doi.org/10.3275/7800

Opdebeeck, C., Quinn, C., Nelis, S., \& Clare, L. (2015). Does cognitive reserve moderate the association between mood and cognition? A systematic review. Reviews in Clinical Gerontology, 25, 181-193. https://doi.org/10.1017/S0959259815000155

Opdebeeck, C., Martyr, A., \& Clare, L. (2016) Cognitive reserve and cognitive function in healthy older people: a meta-analysis. Aging, Neuropsychology, and Cognition, 23, 40-60. https://doi.org/10.1080/ 13825585.2015.1041450

Pettigrew, C., Soldan, A., Li, S., Lu, Y., Wang, M. C., Selnes, O., Moghekar, A., O’Brien, R., Albert, M., \& The Biocard Research Team (2013). Relationship of cognitive reserve and APOE status to the emergence of clinical symptoms in preclinical Alzheimer's disease. Cognitive Neuroscience, 4, 136-142. https://doi.org/10.1080/17588928.2013.831820

Phillips, S., \& Williams, J. (1997). Cognitive impairment, depression and the specificity of autobiographical memory in the elderly. British Journal of Clinical Psychology, 36, 341-347. https://doi. org/10.1111/j.2044-8260.1997.tb01242.x

Piolino, P., Desgranges, B., Benali, K., \& Eustache, F. (2002). Episodic and semantic remote autobiographical memory in ageing. Memory, 10, 239-257. https://doi.org/10.1080/09658210143000353

Plassman, B., Welsh, K., Helms, M., Brandt, J., Page, W., \& Breitner, J. (1995). Intelligence and education as predictors of cognitive state in late life: A 50-year follow-up. Neurology, 45, 1446-1450. https://doi. org/10.1212/wnl.45.8.1446

Prince, M., Acosta, D., Ferri, C., Guerra, M., Huang, Y., Rodriguez, J., Salas, A., Sosa, A., Williams, J., Dewey, M., Acosta, I., Jotheeswaran, A., \& Liu, Z. (2012). Dementia incidence and mortality in middle-income countries, and associations with indicators of cognitive reserve: a 10/66 Dementia Research Group population-based cohort study. Lancet, 380, 50-58. https://doi.org/10.1016/S01406736(12)60399-7

Ramí, L., Valls-Pedret, C., Bartrés-Faz, D., Caprile, C., Solé-Padullés, C., Castellvi, M., Olives, J., Bosch, B., \& Molinuevo, J. (2011). Cognitive reserve questionnaire. Scores obtained in a healthy elderly population and in one with Alzheimer's disease. Revista de neurologia, 52, 195-201.

Richards, M., \& Sacker, A. (2003). Lifetime antecedents of cognitive reserve. Journal of Clinical and Experimental Neuropsychology, 25, 614-624. https://doi. org/10.1076/jcen.25.5.614.14581

Roldán-Tapia, L., García, J., Cánovas, R., \& León, I. (2012). Cognitive reserve, age, and their relation to attentional and executive functions. Applied Neuropsychology: Adult, 19, 2-8. https://doi.org/10. 1080/09084282.2011.595458
Saenz, J., Garcia, M., \& Downer, B. (2018). Late life depressive symptoms and cognitive function among older Mexican adults: the past and the present. Aging \& Mental Health. https://doi.org/10.1080/13 607863.2018.1544214

Satz, P. (1993). Brain reserve capacity on symptom onset after brain injury: A formulation and review of evidence for threshold theory. Neuropsychology, 7, 273-295. https://doi.org/10.1037/08944105.7.3.273

Schwarz, N. (2006). Measurement: Aging and the Psychology of Self-Report. In L. Carstensen \& C. Hartel (Eds.), When I'm 64 (pp. 219-230). Washington: The National Academic Press.

Singh-Manoux, A., Marmot, M., Glymour, M., Sabia, S., Kivimäki, M., \& Dugravot, A. (2011). Does cognitive reserve shape cognitive decline? Annals of Neurology, 70, 296-304. https://doi.org/10.1002/ana.22391

Sivertsen, H., Bjørkløf, G., Engedal, K., Selbæk, G., \& Helvik, A. (2015). Depression and quality of life in older persons: a review. Dementia and Geriatrics Cognitive Disorders, 40, 311-339. https://doi. org/10.1159/000437299

Smart, E., Gow, A., \& Deary, I. (2014). Occupational complexity and lifetime cognitive abilities. Neurology, 83, 2285-2291. https://doi.org/10.1212/WNL. 0000000000001075

Sobral, M., Pestana, M., \& Paúl, C. (2014). Measures of cognitive reserve in Alzheimer's disease. Trends in Psychiatry and Psychotherapy, 36, 160-168. https://doi.org/10.1590/2237-6089-2014-0012

Sokołowska, S., Sokołowski, R., Polak-Szabela, A., Mazur, E., Podhorecka, M., \& Kędziora-Kornatowska, K. (2018). Comparison of the effectiveness of the Montreal Cognitive Assessment 7.2 and the Mini-Mental State Examination in the detection of mild neurocognitive disorder in people over 60 years of age. Preliminary study. Psychiatria Polska, 52, 843-857. https://doi.org/10.12740/PP/68611

Soldan, A., Pettigrew, C., Cai, Q., Wang, J., Wang, M., Moghekar, A., Miller, M., Albert, M., \& the BIOCARD Research Team (2017). Cognitive reserve and long-term change in cognition in aging and preclinical Alzheimer's disease. Neurobiology of Aging, 60, 164-172. https://doi.org/10.1016/j.neurobiolaging.2017.09.002

Stern, Y. (Ed.) (2007). Cognitive reserve - theory and applications. New York, NY: Taylor \& Francis.

Šneidere, K., Montemurro, S., Mondini, S., Harlamova, J., Ulmane, Z., \& Stepens, A. (2018). Cognitive reserve and cognitive performance in healthy Latvian seniors. Society. Integration. Education. Proceedings of the International Scientific Conference, 7, 261-269. https://doi.org/10.17770/sie2018vol1. 3221

Szepietowska, E. (2019). Cognitive reserve as a factor determining the level of cognitive functions in adults: a preliminary report. Journal of Psychia-
Mediatory effect of depression in $C R$-cognitive ability relations 
Ewa Małgorzata Szepietowska try and Clinical Psychology, 19, 32-41. https://doi. org/10.15557/PiPK.2019.0005

Trigg, R., Jones, R., \& Skevington, S. (2007). Can people with mild to moderate dementia provide reliable answers about their quality of life? Age and Ageing, 36, 663-669. https://doi.org/10.1093/ageing/afm077

Valenzuela, M., \& Sachdev, P. (2009). Can cognitive exercise prevent the onset of dementia? Systematic review of randomized clinical trials with longitudinal follow-up. American Journal of Geriatric Psychiatry, 17, 179-187. https://doi.org/10.1097/ JGP.0b013e3181953b57

Van Dijk, K., Van Gerven, P., Van Boxtel, M., Van der Elst, W., \& Jolles, J. (2008). No protective effects of education during normal cognitive aging: results from the 6-year follow-up of the Maastricht Aging Study. Psychology and Aging, 23, 119-130. https://doi.org/10.1037/0882-7974.23.1.119

Vinkers, D., Gussekloo, J., Stek, M., Westendorp, R., \& van der Mast, R. (2004). Temporal relation between depression and cognitive impairment in old age: prospective population based study. British Medical Journal, 329, 881. https://doi.org/10.1136/ bmj.38216.604664.DE

Wheeler, L., \& Reis, H. (1991). Self-recording of everyday life events: origins, types, uses. Journal of Personality, 59, 339-354. https://doi.org/ 10.1111/j. 1467-6494.1991.tb00252.x

Wild, K., Mattek, N., Austin, D., \& Kaye, J. (2015). "Are You Sure?": Lapses in self-reported activities among healthy older adults reporting online. Journal of Applied Gerontology, 35, 627-641. https://doi. org/10.1177/0733464815570667

Wilson, R., Yu, L., Lamar, M., Schneider, J., Boyle, P., \& Bennett, B. (2019). Education and cognitive reserve in old age. Neurology, 92, e1041-e1050. https:// doi.org/10.1212/WNL.0000000000007036

Zahodne, L., Glymour, M., Sparks, C., Bontempo, D., Dixon, R., MacDonald, S., \& Manly, J. (2011). Education does not slow cognitive decline with aging: 12-year evidence from the Victoria longitudinal study. Journal of the International Neuropsychological Society, 17, 1039-1046. https://doi.org/10.1017/ S1355617711001044

Zaninotto, P., Batty, G., Allerhand, M., \& Deary, I. (2018). Cognitive function trajectories and their determinants in older people: 8 years of follow-up in the English Longitudinal Study of Ageing. Journal of Epidemiology and Community Health, 72, 685-694. https://doi.org/10.1136/jech-2017-210116 